\title{
Representações Acerca da Maternidade no Contexto da Depressão Pós-Parto
}

\author{
Representations Concerning Motherhood in Postpartum Depression Context
}

\author{
Daniela Delias de Sousa ${ }^{*}$, , Luiz Carlos $\operatorname{Prado}^{b} \&$ Cesar Augusto Piccinini ${ }^{a}$ \\ ${ }^{a}$ Universidade Federal do Rio Grande do Sul, Porto Alegre, Brasil \\ $\&{ }^{b}$ Instituto da Família de Porto Alegre, Porto Alegre, Brasil
}

\begin{abstract}
Resumo
O presente estudo investigou as representações acerca da maternidade no contexto da depressão pós-parto. Participaram do estudo duas mães encaminhadas para a realização de uma psicoterapia breve pais-bebê devido à presença de depressão no primeiro ano de vida de suas filhas. Entrevistas de avaliação realizadas antes da psicoterapia foram analisadas a partir dos quatro eixos interpretativos que constituem a constelação da maternidade, proposta por Stern (1997): vida-crescimento; relacionar-se primário; matriz de apoio; e reorganização da identidade. Nos relatos de ambas as mães apareceram representações acerca do sentimento de não ser capaz de cuidar do bebê logo após o nascimento, de ser pouco apoiada pelo companheiro, bem como uma reavaliação do relacionamento com suas próprias mães e com seus cônjuges. Verificou-se também que as representações de cada mãe apontaram para uma estreita associação entre seus conflitos pregressos e a interação atual com o marido e com o bebê.

Palavras-chave: Representações maternas; Depressão pós-parto; Interação mãe-bebê.
\end{abstract}

\begin{abstract}
The present study investigated the representations concerning motherhood in the context of postpartum depression. The study sample was composed by two mothers referred to a brief parent-infant psychotherapy due to depression during the first year of their daughters' life. Interviews of evaluation carried out before psycotherapy were analyzed according to four interpretative axes of the motherhood constellation proposed by Stern (1997): life-growth; primary relatedness; supporting matrix; and identity reorganization. In the stories of both mothers there were representations concerning the feeling of not being capable to take care of their baby after birth, of being little supported by their husbands, as well as a reevaluation of the relationship with their own mothers and spouses. It was verified that the representations revealed a close association between their past conflicts and the current interaction with the husband and with the baby. Keywords: Maternal representations; Postpartum depression; Mother-infant interaction.
\end{abstract}

O processo de tornar-se mãe pode significar a realização de um profundo realinhamento psíquico, tendo em vista a necessidade de adaptações frente à assunção de novos papéis. Com a chegada de um filho, a mulher, por ser na maioria das vezes a principal cuidadora do bebê, vê-se diante de uma reorganização de seu mundo representacional. Essa reorganização pode implicar na reelaboração de vários esquemas a respeito de si mesma, sobre o bebê, sobre o companheiro e também sobre a sua família de origem, os quais podem concorrer para o aparecimento de sintomas de depressão pós-parto (Stern, 1997).

A depressão pós-parto comumente associada ao nascimento de um bebê refere-se a um conjunto de sintomas

\footnotetext{
* Endereço para correspondência: Universidade Federal do Rio Grande, Avenida Itália, KM 8, Campus Carreiros, Rio Grande, RS, Brasil, CEP 96201-900. Tel.: (53) 3293 5076. E-mails: daniela.delias@gmail.com e piccinini@portoweb.com.br
}

que iniciam geralmente entre a quarta e a oitava semana após o parto, atingindo de 10 a $15 \%$ das mulheres, podendo persistir até o segundo ano de vida da criança (Klaus, Kennel, \& Klaus, 2000). De acordo com os autores, os sintomas incluem irritabilidade, choro freqüente, sentimentos de desamparo e desesperança, falta de energia e motivação, desinteresse sexual, transtornos alimentares e do sono, a sensação de ser incapaz de lidar com novas situações, bem como queixas psicossomáticas (Klaus et al., 2000).

O impacto da depressão pós-parto para as interações iniciais entre a mãe e o bebê tem recebido crescente atenção dos pesquisadores do desenvolvimento infantil nas últimas décadas. A maior parte dos estudos desenvolvidos tem investigado as implicações da depressão da mãe para a qualidade da interação com o bebê e, conseqüentemente, para o desenvolvimento posterior da criança (Schwengber \& Piccinini, 2003). Outros têm buscado ampliar a compreensão a respeito dos fatores associados à depressão materna, estendendo suas investigações à 
exploração das representações acerca da maternidade de mulheres que apresentam sintomas de depressão no primeiro ano após o nascimento do bebê (Brown, Lumley, Small, \& Astbury, 1994; Lovejoy, Graczyk, O'Hare, \& Neuman, 2000; Reading \& Reynolds, 2001; Schwengber \& Piccinini, 2005).

O termo representação tem sido referido na literatura a partir de diferentes vertentes teóricas, as quais fundamentam as especulações de filósofos, psicólogos, sociólogos e antropólogos a respeito da construção da subjetividade humana. No presente artigo, o sentido dado a este termo contempla fundamentalmente as concepções de Stern (1997) sobre o tornar-se mãe. Assim, justifica-se a necessidade de se enfatizar as principais contribuições do autor a esse respeito.

Para Stern $(1992,1997)$, as representações podem ser compreendidas como um aspecto necessário e normal do desenvolvimento e da experiência com os outros. $\mathrm{O}$ autor considera o mundo representacional dos pais como o primeiro elemento a ser examinado na situação clínica, devido à sua importância na determinação da natureza do relacionamento com o bebê. Para ele, este mundo representacional refere-se a como os pais experimentam e interpretam subjetivamente os eventos objetivamente disponíveis na interação com o bebê, incluindo os seus comportamentos e os comportamentos do filho. As representações parentais incluem as interações atuais e também as lembranças infantis, fantasias, medos e expectativas em relação ao bebê. Para Stern, estas se formam e se organizam na experiência interativa, principalmente na experiência subjetiva de estar-com outra pessoa, a qual pode ser tanto uma experiência interativa real como fantasiada.

À modificação e reorganização de esquemas experimentados pela mãe após o nascimento do bebê, Stern (1997) denominou "constelação da maternidade". Conforme o autor, esta constelação refere-se a uma nova organização psíquica que determinará uma série de ações, sensibilidades, medos, fantasias e desejos da mãe, tornando-se o eixo organizador dominante de sua vida psíquica e empurrando para o lado as organizações ou complexos nucleares anteriores, como o Complexo de Édipo.

A constelação da maternidade refere-se a três preocupações e discursos diferentes, mas relacionados: o discurso da mãe com a própria mãe; seu discurso consigo mesma; e seu discurso com o bebê (Stern, 1997). De acordo com o autor, ao fazer uma reelaboração em torno dessa trilogia, quatro temas se fazem presentes: vidacrescimento; relacionar-se primário; matriz de apoio; $\mathrm{e}$ reorganização da identidade. Em relação ao tema vidacrescimento, a questão central para a mãe logo após o nascimento do bebê é se terá condições de mantê-lo

${ }^{1}$ Inúmeros relatos podem ser encontrados na tese de doutorado da primeira autora, que por questões de espaço não foram destacados a seguir. vivo e se poderá promover o seu desenvolvimento físico. Já o tema do relacionar-se primário diz respeito ao envolvimento sócio-emocional da mãe com o bebê e se caracteriza pela sua preocupação em poder relacionar-se com ele de um modo não-verbal. $\mathrm{O}$ tema da matriz de apoio refere-se à necessidade da mãe de criar, permitir, aceitar e regular uma rede de apoio protetora para que possa manter o bebê vivo e promover seu desenvolvimento psíquico-afetivo. Finalmente, o tema da reorganização da identidade refere-se às preocupações da mãe com o fato de ser ou não capaz de transformar sua auto-identidade para permitir e facilitar as funções maternas. Sendo assim, inclui as representações sobre a mudança de status de filha para mãe, de esposa para progenitora e de profissional para mãe de família, assim como sobre os seus modelos de parentagem e cuidados que teve da própria mãe.

Como pode ser visto, o caráter conflituoso das mudanças experimentadas a partir do nascimento de um bebê pode representar, para algumas mulheres, um fator de risco para a depressão materna. Nesse sentido, o presente estudo investigou as representações acerca da maternidade de mães com indicadores de depressão no período que antecedeu a realização de uma psicoterapia breve paisbebê, particularmente no que se refere aos quatro temas que constituem a constelação da maternidade (Stern, 1997). A expectativa inicial era de que as mães que buscaram ajuda para a sua depressão relatassem dificuldades a respeito da maternidade, tais como: o sentimento de não ser capaz de cuidar do bebê, de não conseguir entender as suas necessidades, de se sentir pouco apoiada ou vulneráveis frente às mudanças advindas da maternidade.

\section{Método}

\section{Participantes}

Participaram deste estudo duas famílias cujas mães apresentavam indicadores de depressão moderada, com base nos escores do Inventário Beck de Depressão (Beck \& Steer, 1993) e na realização de uma entrevista clínica diagnóstica (Grupo de Interação Social, Desenvolvimento e Psicopatologia \& Núcleo de Infância e Família [GIDEP \& NUDIF], 2003a). A primeira família era constituída por Paula (31 anos; secretária; ensino superior incompleto), seu marido Valdir (34 anos; bancário; ensino superior incompleto) e a filha Giovana (sete meses). A segunda família era constituída por Andréa (32 anos; artefinalista; ensino médio completo), seu marido Luciano (32 anos; auxiliar de escritório; ensino médio completo) e a filha Laura (seis meses).

Os bebês não apresentaram complicações ao nascimento. As duas famílias residiam na região metropolitana de Porto Alegre e tinham nível socioeconômico médio e médio baixo, respectivamente. O contato inicial com a primeira família foi feito por indicação de uma psicóloga 
enquanto a segunda foi encaminhada pela equipe de um dos hospitais públicos contatados.

As duas famílias participantes faziam parte do projeto intitulado "O Impacto da Psicoterapia para a Depressão pós-parto e para a Interação Pais-Bebê: Estudo Longitudinal do Sexto ao Décimo Segundo Mês Vida do Bebê" (Piccinini et al., 2003), que acompanhou, em psicoterapia, 23 famílias, cujas mães apresentavam depressão pósparto. O estudo investigou uma série de fatores associados à depressão materna, tais como: experiência da maternidade e paternidade, qualidade do relacionamento conjugal, interação mãe-bebê e pai-bebê, bem como o impacto de uma psicoterapia breve pais-bebê para estas famílias. Antes e depois da psicoterapia as mães, pais e o bebê foram extensamente avaliados. Exceto no caso de mães solteiras, a presença do pai era obrigatória, pelo menos durante a avaliação inicial, onde entre outros aspectos se avaliava também a sua depressão, e todos eram encorajados a participar das sessões de psicoterapia. Os pais e mães eram todos adultos e de escolaridade e níveis socioeconômicos variados. Os bebês tinham entre um e doze meses de idade, quando ingressavam no estudo, e não apresentavam intercorrências clínicas.

Como parte do projeto longitudinal foram inicialmente contatadas 28 famílias cujas mães apresentavam depressão moderada ou grave, de acordo com avaliação feita pelo Inventário Beck de Depressão (Beck \& Steer, 1993; Cunha, 2001). Dentre estas, cinco desistiram ainda na fase de avaliação inicial. Entre as 23 que fizeram a avaliação inicial e que iniciaram a psicoterapia, $19(83 \%)$ passaram por todo o processo psicoterapêutico e participaram de pelo menos uma das avaliações pós atendimento, realizadas depois de uma semana (47\%) e seis meses (53\%) após o término da psicoterapia. Das famílias que iniciaram a psicoterapia, quatro desistiram do atendimento ao longo do atendimento. As 28 famílias inicialmente contatadas foram encaminhadas por unidades sanitárias de saúde (11\%), por hospitais da rede pública de Porto Alegre (36\%), através da mídia (32\%) e por indicação (21\%). O estudo foi aprovado pelo Comitê de Ética da Universidade Federal do Rio Grande do Sul ([UFRGS], Proc. 200396), Hospital de Clínicas de Porto Alegre (Proc. 03068) e Grupo Hospitalar Conceição (Proc. 88/03).

As duas mães que participaram do presente estudo foram escolhidas por terem sido atendidas pela primeira autora. Ambas apresentavam indicadores de depressão moderada, o que pôde ser constatado pelos escores obtidos no Inventário Beck de Depressão (Paula com Beck = 23 pontos e Andréa com Beck = 22 pontos). Este instrumento é composto por itens que contemplam diferentes alternativas de resposta a respeito de como o sujeito tem se sentido, e que correspondem a diferentes níveis de gravidade da depressão. A soma dos escores dos itens individuais fornece um escore total, que por sua vez constitui um escore dimensional da intensidade da depressão, que pode ser classificado nos seguintes níveis: mínimo (até
11 pontos), leve (de 12 a 19 pontos), moderado (de 20 a 35 pontos) ou grave (acima de 36 pontos). A entrevista diagnóstica também apontou para a presença de um quadro depressivo em ambos os casos. Paula relatou sentimentos de tristeza, desvalia (principalmente em relação ao próprio corpo), ansiedade, culpa em relação a precisar deixar a filha em função do trabalho, transtornos do sono e do apetite, e o sentimento de sobrecarga nos cuidados com Giovana. A entrevista diagnóstica realizada com Andréa também apontou para a presença de um quadro depressivo, principalmente em virtude de sua apatia e das queixas de cansaço, falta de apetite, de sono e de energia. Além disso, Andréa relatou um sentimento difuso de preocupação e de tristeza, bem como evidenciou descuido em relação ao próprio corpo e à sua aparência (o que inclusive estava sendo apontado por seus colegas de trabalho).

\section{Delineamento, Procedimentos e Instrumentos}

Utilizou-se um delineamento de estudo de casos (Stake, 1994), com o objetivo de investigar as representações acerca da maternidade nestas duas mães que apresentavam indicadores de depressão moderada. Em cada um dos casos buscou-se examinar as representações maternas relacionadas aos quatro temas que constituem a constelação da maternidade (Stern, 1997): (a) vida-crescimento; (b) relacionar-se primário; (c) matriz de apoio; e (d) reorganização da identidade. Além disso, foram examinadas as semelhanças e particularidades entre os casos.

Como já assinalado acima, o projeto longitudinal do qual este estudo faz parte envolveu uma fase inicial de avaliação que antecedeu a realização de uma psicoterapia breve pais-bebê. Para fins do presente estudo, foram considerados apenas alguns dos instrumentos utilizados na fase inicial. Detalhes dos demais instrumentos podem ser encontrados em Piccinini et al. (2003). Seguindo o procedimento geral do projeto longitudinal, num primeiro encontro as mães responderam à Ficha de Contato Inicial (GIDEP \& NUDIF, 1998) e, por preencherem os critérios de inclusão no presente estudo, assinaram também o Consentimento Livre e Esclarecido (GIDEP \& NUDIF, 2003b. Posteriormente, responderam ao Inventário Beck de Depressão (Beck \& Steer, 1993; Cunha, 2001) e à Entrevista Diagnóstica (GIDEP \& NUDIF, 2003a) para confirmar os indicadores de depressão materna. Além disso, responderam à Entrevista sobre a Gestação e o Parto (GIDEP \& NUDIF, 2003c), que investigou as representações maternas acerca do período da gravidez, do parto e dos primeiros dias com o bebê, e à Entrevista sobre a Experiência da Maternidade (GIDEP \& NUDIF, 2003d), que investigou as representações sobre o bebê, sobre o apoio recebido do cônjuge e de outras pessoas, bem como sobre às mudanças advindas com a maternidade. Estas entrevistas, semi-estruturadas, eram realizadas de forma semi-dirigida. 


\section{Resultados e Discussão}

Análise de conteúdo qualitativa (Laville \& Dione, 1999) foi utilizada para investigar as representações acerca da maternidade nos relatos das duas mães. Nesta análise recorreu-se principalmente a concepção de Stern (1997) a respeito da constelação da maternidade.

Para examinar as representações maternas, todas as entrevistas foram inicialmente transcritas. A leitura inicial do material possibilitou a realização de anotações sobre o que parecia se destacar nas falas das mães. Numa segunda leitura do material, buscou-se identificar referências em relação aos temas da constelação da maternidade (Stern, 1997). Uma terceira leitura permitiu a produção do relato do material, destacando-se as falas das mães que pareciam exemplificar de forma mais relevante as suas representações. Para fins de exposição, descrevem-se conjuntamente as representações maternas dos dois casos analisados de acordo com os temas propostos por Stern $(1997)^{1}$.

\section{Vida-crescimento}

Este tema foi identificado em alguns relatos de ambas as mães quando se referiram aos seus sentimentos durante a gestação: "Se ela ia nascer perfeita, né. Acho que essa é a preocupação de toda mãe" (P, para Patrícia); "Eu pensava se ela ia nascer perfeita. Eu acho que qualquer mãe fica pensando se vai ser normal. É que eu fumei um pouco, então eu ficava preocupada com isso" (A, para Andréa).

Também se verificou que ambas as mães referiram o sentimento de alívio ao verem que suas filhas nasceram com saúde: "Quando botaram ela perto de mim, que eu vi que ela tava viva, que ela tava bem... foi um alivio" (P); "Pela barra que eu passei [rejeição do marido ao saber que o bebê seria uma menina] ela é uma criança fora de série, perfeita" (A).

Ambas as mães relataram que nos primeiros dias após o parto sentiram-se preocupadas em relação à sua capacidade de cuidar adequadamente de seus bebês:

Eu não me enxergava como mãe, eu olhava para a Giovana, eu achava assim 'E agora? Como é que eu vou cuidar dela? Ela é muito pequena, eu não vou ter como cuidar dela ... '. Ah, me sentia uma incompetente. Imagina, não vou conseguir, imagina, quase matei a guria de fome. (P).

Ai, me vinha um monte de coisa ... porque eu tinha receio de não ter o cuidado que ela merecia. Aquele medo de que a mãe não faça o bastante, né? De ter mais jeito... como é que eu vou te dizer? Essas preocupações assim, normais, né? Se tiver cólica, se eu vou saber, esse tipo de coisa. (A).

Como pode ser visto, o tema da vida-crescimento foi trazido por ambas as mães nas entrevistas quando falaram sobre o sentimento de inadequação em relação aos cuidados com o bebê nos primeiros dias após o nasci- mento. Estes relatos apóiam a concepção de Stern (1997) de que preocupações com a manutenção da vida do bebê e com o seu desenvolvimento físico são esperadas nesse período. Para o autor, o medo de que o bebê morra ou que não coma é natural após o nascimento e nos meses iniciais de vida do bebê, e comumente está associado a um sentimento de inadequação, de não ser uma mãe suficientemente protetora.

Embora preocupações com a vida-crescimento do bebê sejam esperadas entre as mães no período do pós-parto, independente da presença de depressão, a literatura aponta para uma importante associação entre a presença de depressão materna associada a um maior numero de preocupações com a saúde e o desenvolvimento do bebê (Brown et al., 1994; Klaus et al., 2000; Romito, SaurelCubizolles, \& Lelong, 1999; Schwengber \& Piccinini, 2005). Da mesma forma, alguns estudos apontam que mães deprimidas definiram-se como menos competentes para cuidarem dos seus bebês do que mães não-deprimidas (Milgron \& McCloud, 1996), assim como relataram menos confiança e satisfação com o desempenho do papel materno (Anderson, Fleming, \& Steiner, 1994; Brown et al., 1994; Fowles, 1996; Panzarine, Slater, \& Scharps, 1995).

\section{Relacionar-se Primário}

Este tema apareceu nas referências de ambas as mães acerca de como avaliavam o desenvolvimento emocional de seus bebês e a interação mútua. Paula considerou que na maioria das vezes compreendia os sinais de sua filha, mas entendia que estavam em um processo de reconhecimento: "Ela presta atenção na gente. Quando a gente fala com ela, ela ri para a gente. Parece que ela responde, né? A gente ainda tá se conhecendo, né" (P). Contudo, verificou-se também o seu sentimento de angústia quando da dificuldade em entender os sinais da filha:

O difícil é quando ela tá com dor, com alguma dor, incomodada, que nem essa noite: não imaginava o que podia ser que ela tinha ... Ai, quando ela tá desanimadinha assim, tá chorando, a gente não sabe o que é isso, chega até a me irritar um pouco isso. A gente tem que se controlar, né, mas chega a me angustiar [dirigindo-se à filha]: 'Né, filha? A mamãe não sabe o que tu quer dizer, né?'. (P).

Andréa também considerou que tinha uma boa interação com a filha. Conforme falou, procurava estar sempre próxima dela, pegando-a no colo e conversando com ela sempre que possível. Como exemplo dessa interação, falou sobre quando cantava para a filha, que costumava reagir sorrindo. Conforme as suas palavras, "Laura [a filha] foi a única coisa boa de tudo isso [referindo-se à rejeição do companheiro]".

É interessante destacar que ambas as mães fizeram referência à necessidade de dar mais atenção às suas filhas: A gente chega em casa de noite, tem um monte de coisa para fazer, né, e tem que dar atenção para ela 
também. E ai às vezes ela fica no carrinho e a gente fica conversando e não conversa com ela, então eu acho que é isso que ela não gosta, eu tinha que dar mais atenção. $(\mathrm{P})$.

Eu chego às quatro da tarde. Mas aí já chego na função. Dai já tem que dar banho. Eu fico um pouquinho com ela, né, porque ela sente muito a minha falta. Mesmo assim eu não dou a atenção que ela quer de mim. Porque sempre tem alguma coisa pra arrumar. Eu também não dou a atenção que ela merece, porque eu sinto que ela sente falta. Quando eu pego ela, então ela fica quieta. Aí coloco no carro e ela já começa... [a resmungar]. (A).

As falas de ambas as mães a respeito de suas impressões sobre o temperamento de suas filhas denotaram alguns sentimentos ambivalentes. Ao mesmo tempo em que considerava a filha uma criança feliz, tranqüila e "dada", Paula entendia que a filha estava sempre "colada" nela. Já Andréa, que também considerou a sua filha uma criança calma e tranqüila, relatou que ela poderia vir a ter um temperamento difícil porque o seu companheiro era uma pessoa muito difícil.

Também se verificou no relato das duas mães preocupações em assegurar um bom desenvolvimento para suas filhas. Elas destacaram suas preocupações de que os desentendimentos que tinham com os seus cônjuges poderiam afetar o desenvolvimento de seus bebês:

Tem dias que eu tô mais preocupada, que eu fico pensando assim, 'bah, como é que vai ser a educação dela? Como é que eu e o Valdir [marido] vamos estar sintonizados para passar as coisas para ela? Como é que a gente...' para dar bom exemplo, sabe? Isso é o que mais me preocupa. $(\mathrm{P})$.

No caso de Andréa esta preocupação assumiu um tom mais grave, uma vez que ela e o marido pouco se falavam. Desde o término da sua licença-maternidade a filha ficara aos cuidados do marido durante o dia. Este trabalhava à noite, sendo que costumava dormir das cinco horas até ao meio-dia. Quando acordado, dedicava o seu tempo a cuidar de alguns animais que mantinha em casa. Com isso, a filha também dormia durante toda a manhã e grande parte da tarde. Quando despertava, costumava ficar quieta no berço até voltar a dormir novamente. Andréa entendia que sua filha estava apática com esta situação. Cabe ressaltar que Andréa foi encaminhada para o atendimento por sua mãe, que estava preocupada tanto com a apatia dela como com a da neta.

A análise dos relatos possibilitou a identificação de ao menos uma importante representação materna acerca do bebê em cada um dos casos. Para Paula, a filha estaria "colada" a ela. Sendo assim, inferiu-se inicialmente que essa representação estaria associada a uma fantasia de que importantes perdas sofridas por sua mãe poderiam ser repetidas na sua história com a própria filha. A sua mãe havia sofrido um aborto espontâneo e também a perda de uma filha com seis meses de vida, e seus pais cos- tumavam comentar que talvez tivessem tido uma sorte diferente se a mãe não trabalhasse fora à época.

Em Andréa, se verificou a representação de um bebê apático e pouco estimulado que poderia vir a se tornar "difícil" dadas as circunstâncias adversas da gravidez e dos primeiros meses após o parto, particularmente em relação aos problemas conjugais.

A ambivalência identificada no discurso de ambas as mães remete à concepção de que os esquemas maternos centrados no bebê podem incluir vários bebês que se sobrepõem na mente da mãe, sendo cada um levemente diferente do outro (Stern, 1997). Assim, esquemas diferentes se baseiam em momentos interativos diferentes, reais ou fantasiados, que podem ocorrer entre a mãe e o bebê, e na ativação desses esquemas o temperamento do bebê teria um papel crucial. Parece importante destacar que a literatura tem sido consistente ao sugerir uma estreita associação entre a presença de depressão materna e relatos negativos acerca do temperamento do bebê (Brown et al., 1994; Cutrona \& Troutman, 1986; Field, Morrow, \& Adlestein, 1993; Hopkins, Campbell, \& Marcus, 1987; Mebert, 1991; Whiffen, 1990). Embora as representações apontassem para conteúdos distintos, em ambos os casos verificou-se que estavam atreladas às histórias de vida das mães, sugerindo uma estreita associação entre os seus conflitos pregressos e a interação atual com o bebê.

\section{Matriz de Apoio}

O tema da matriz de apoio foi amplamente abordado por ambas as mães. Paula demonstrou reconhecer que foi apoiada por várias pessoas durante a gestação, o parto e o puerpério, particularmente por seu marido e pelos familiares. Contudo, ao mesmo tempo em que relatou sentirse apoiada pelo marido, avaliou que este também a atrapalhou, em virtude de ser "estressado".

Ao falar sobre como se sentia no momento da entrevista em relação ao apoio do companheiro, Paula reconheceu e elogiou o apoio do marido nos cuidados com a filha. Porém, ela demonstrou certa ambivalência em relação a esse apoio. Ao mesmo tempo em que afirmou sentir-se aliviada ao ser ajudada, referiu que se sentia "dispensável" nas vezes em que ele assumia os cuidados da filha. Além disso, embora tenha considerado esse apoio fundamental, queixou-se da dificuldade do marido para tomar decisões e também da sua resistência em ajudá-la com os serviços domésticos, com o que acabava por se sentir sobrecarregada.

Da mesma forma como mencionou o apoio do marido, enfatizou em seus relatos a necessidade que sentiu de ter o apoio de sua mãe, principalmente ao se referir às dificuldades enfrentadas no período pós-parto: "Minha mãe falava em ir embora, eu chorava. Eu imaginava assim que eu não ia precisar de ninguém, que eu ia me virar sozinha, que eu ia dar conta de tudo" (P).

Em relação às suas impressões sobre como as pessoas que a apoiavam a viam como mãe, Paula afirmou que 
imaginava ser vista como uma mãe dedicada, responsável e preocupada. Essa impressão não se confirmou apenas em relação à babá da filha, uma vizinha que cuidava dela durante o dia. Embora tenha relatado que se sentia muito satisfeita com os cuidados prestados por essa senhora, afirmou que muitas vezes sentia-se culpada por deixar a filha e "sufocada" pelo que considerava um excesso de zelo da babá: "Acho que ela me vê como uma relapsa $[$ risos]" (P).

O tema da matriz de apoio também foi amplamente referido por Andréa. Se, por um lado, pôde contar com o apoio irrestrito de seus pais e de seus irmãos desde a gestação até aquele momento, o mesmo não poderia ser dito em relação ao seu companheiro. Segundo o seu relato, depois da revelação do sexo do bebê, o comportamento do marido teria modificado radicalmente, no sentido de que passou a ignorar a esposa e a filha. Tal informação foi confirmada por Luciano em sua entrevista.

Ao falar sobre a organização da rotina de cuidados com a filha, Andréa reconheceu que o marido estava se esforçando para cuidar da filha, mas considerou que esse esforço era insuficiente frente a todo o sofrimento que havia causado ao rejeitá-la. Andréa reconheceu também que ele fazia algumas tentativas no sentido de conversarem, mas afirmou que, da sua parte, não havia mais nenhum interesse em retomar a relação: "Eu acho que se não mudou agora, com o nascimento dela, com ela ali presente, acho que não tenho mais... é como eu te falei: morreu, sabe? Vai morrendo, morrendo" (A).

É interessante destacar as impressões de Andréa a respeito de como imaginava ser vista pelas pessoas que a apoiavam. Ao falar sobre como essas pessoas em geral a viam, mencionou que geralmente era elogiada, principalmente por ter uma "filha maravilhosa", de quem sabia cuidar. Em relação ao marido, mencionou que ele provavelmente não teria nada para reclamar, tendo em vista que ela só não fazia mais pela filha em função da falta de tempo e de condições. Já em relação à sua mãe, Andréa mencionou que talvez não estivesse atendendo às suas expectativas: "Eu acho que ela acha que eu sou meio fraca. Não digo fraca, mas acho que ela esperava mais. Eu não sei como explicar, mas eu sei que ela tá com um peso nos ombros" (A).

Embora tanto Paula como Andréa tenham feito queixas em relação ao apoio de seus companheiros, verificou-se que essas queixas adquiriram uma tonalidade mais grave na segunda família. Para Feldman (2000), a insatisfação com o cônjuge pode contribuir para a pobreza do diálogo e para a baixa influência mútua entre marido e mulher, impedindo inclusive que se apercebam da tristeza do outro.

Os relatos destas mães apóiam os resultados de dois estudos que compararam as impressões de mães com e sem depressão em relação à experiência da maternidade (Brown et al., 1994; Schwengber \& Piccinini, 2005). Para estes autores, as mães dos dois grupos reconheceram a presença de uma rede de apoio social, embora entre as mães deprimidas tenham sido verificados relatos que denotavam sentimentos ambivalentes e maior insatisfação com o apoio do companheiro e de outras pessoas.

Também nas mulheres deste estudo verificou-se o sentimento de culpa das mães pelo afastamento de suas filhas em função do trabalho. De fato, a literatura aponta que muitas vezes o conflito resultante da necessidade de conciliar o trabalho e o exercício da maternidade muitas vezes resulta em sentimentos de culpa e inadequação (Langer, 1986). Apoiando essa concepção, Hock e DeMeis (1990) ressaltaram que a crença feminina na maternidade como um instinto estaria associada a maior ansiedade frente à separação do bebê e que o sentimento de ser a única pessoa capaz de cuidar do bebê implicaria na resistência e até rejeição de cuidados alternativos.

\section{Reorganização da Identidade}

O tema da reorganização da identidade apareceu nas referências de Paula a respeito da sua dificuldade em enfrentar uma série de transformações:

Eu tô me sentindo... ao mesmo tempo em que eu tô feliz, eu me sinto com muita responsabilidade assim, me sinto sobrecarregada. Na verdade, a gente acumula, né, muitas coisas e mais a atividade de ser mãe. A gente é mulher, a gente é mãe, e a gente é profissional, e a gente é filha, é irmã, isso é complicado. O mais dificil é conciliar essas coisas todas. Ah, mudou tudo, tudo, até a maneira de ver a vida assim, né. (P).

Em sua reflexão sobre ser mãe, Paula considerou estar assustada com o fato de ter que "formar outra pessoa" em um momento no qual via a si mesma como tendo "coisas" a resolver. Além disso, sua reflexão a respeito das transformações experimentadas incluiu também a sua insatisfação com as mudanças observadas no próprio corpo: "Não me gosto, não tenho nem vontade de me olhar no espelho. Acho horrivel, tô me sentindo feia" (P).

É interessante pensar que uma das mudanças mais enfatizadas por Paula referiu-se aos seus sentimentos em relação à própria mãe:

Mudou, eu senti que eu fiquei assim mais próxima da minha mãe, né, porque a gente sempre teve uma distância assim . . . a minha mãe sempre ficou com um papel mais da bruxa, entendeu? O papel pior ficou para ela, até pelo perfil dela, meu pai já é mais acomodado. (P).

Segundo o seu relato, ela imaginava que na sua experiência como mãe teria uma tendência a ser como a própria mãe, embora se "policiasse" para não sê-lo. Isso por considerar que, embora os cuidados de sua mãe tenham sido positivos, entendia que ela tinha sido muito repressora.

Em relação às mudanças no relacionamento com o marido, Paula ressaltou que os desentendimentos se agravaram após o nascimento da filha, o que atribuiu ao cansaço, a falta de tempo para estarem a sós e também a pouca tolerância do marido. Assim, expressou um desejo de que alguma coisa mudasse, tendo em vista o sofrimento de ambos. 
Paula contou ainda que sentia vontade de chorar por qualquer motivo, como havia acontecido recentemente no seu trabalho, quando, em uma dada situação, sentiuse incompetente para realizar uma determinada tarefa. Em relação a isso, mencionou que a sua posição no trabalho também havia mudado depois do nascimento da filha, motivo pelo qual sentia que estava "sobrando".

Por outro lado, não identificou muitas mudanças no relacionamento com os amigos, a não ser pelo fato de que, após o nascimento da filha, ela e o marido não estavam fazendo alguns programas com os amigos, como viagens e festas.

Referências a este tema foram identificadas inicialmente nas falas de Andréa acerca do sentimento de que seus pais teriam ficado preocupados com a sua gravidez por considerarem que ela era uma pessoa bastante problemática, justamente por ser muito introvertida e por não demonstrar iniciativa na resolução de problemas. Porém, ela julgou que o fato de ter um bebê estaria tornando mais urgente a necessidade de se posicionar principalmente em relação às dificuldades conjugais: "Eu sou muito acomodada, como eu te falei, né? Eu vou deixando, vou deixando, assim não vai melhorar, né? Ai vai se tornando uma bola de neve, como se transformou" (A).

Ainda em relação à reorganização da vida conjugal, o relato de Andréa permite pensar que seu marido também se referia à sua eventual dificuldade em expor as suas idéias e sentimentos: "Ele acha que as poucas coisas que eu falo são devidas às pessoas, que colocaram na minha cabeça. Diz que eu não tenho uma opinião formada, uma opinião própria”. Porém, Andréa buscou defender-se da constatação do marido, dizendo que, na verdade, era uma pessoa calma e que tentava não perder o controle nas vezes em que divergiam.

Andréa considerou que sua mãe também era uma pessoa preocupada com os problemas, mas que, diferente dela, tomava a iniciativa de resolvê-los. A análise de suas falas permite constatar que Andréa tinha em sua mãe um modelo a ser seguido. Para ela, sua mãe era uma pessoa ativa e decidida, apesar de muito emotiva. Já o pai era considerado uma pessoa "pacata", sendo que Andréa atribuía o fato de ser calma a uma identificação com ele.

Andréa considerou que, de certa forma, o relacionamento com a mãe havia mudado depois do nascimento da filha. Em seu relato foi possível identificar a preocupação em poupar a mãe do conhecimento de seus problemas, possivelmente em função do que já estava acontecendo: ela estava intervindo ativamente na relação entre Andréa e seu marido, cobrando-lhes a resolução de seus problemas.

É interessante mencionar ainda que quando falou a respeito das suas representações sobre como era cuidada por sua mãe, Andréa falou sobre ficar só e não incomodar, justamente o que mais parecia estar afetando sua própria mãe naquele momento em relação a um possível abandono da neta: "Eu não lembro de quase nada, mas ela dizia que eu me embalava no carrinho sozinha, que eu dormia sozinha no carrinho. Eu sempre fui... como é que eu vou dizer? Independente. Nunca dei trabalho" (A).

Em relação a mudanças referentes à profissão, Andréa contou que havia retornado recentemente ao trabalho, sendo que falou a respeito desse retorno:

Não, eu tô conseguindo tocar. Até porque a gente precisa trabalhar. Eu nunca parei, eu nunca pensei assim que quando eu tivesse filho eu parasse de trabalhar. Claro que eu sinto falta de ficar com ela, sabe? Quando eu tô lá no serviço eu fico lembrando do rostinho dela, sabe? Ás vezes eu saio de manhã e ela tá acordada, com o pescoço levantado, querendo me ver. Então é um troço que dá. (A).

De acordo com o seu relato, diversos colegas teriam comentado que ela havia mudado muito desde a gravidez:

Disseram que eu fiquei mais triste. Eu não tinha mais aquela alegria que eu tinha antes. E até agora, no serviço, tenho colegas que me falam que eu tô mais séria, que eu não brinco mais, que eu baixo a cabeça. (A).

Andréa afirmou que, de fato, sentia que naquele momento vivia apenas para a filha. Conforme relatou, só pensava no bem-estar dela, tendo esquecido de si mesma. Um exemplo disso, é que não estava preocupada com o seu próprio corpo, embora a sua mãe e algumas colegas de trabalho tivessem comentado que antes de ter a filha costumava se cuidar mais. Por fim, ao tentar definir como estava se sentindo como mãe naquele momento, Andréa contou que, ainda que fosse uma experiência boa, sentiase muito assustada.

Como pode ser visto, o tema da reorganização da identidade foi identificado nas representações de ambas as mães, uma vez que o processo de realinhamento psíquico desencadeado a partir do nascimento do bebê era evidente. Essa constatação remete à concepção de Stern (1997) de que com o nascimento do bebê o status e a identidade básica da mãe sofrem uma importante modificação, na medida em que se dá um processo radical de reorganização das representações do self como mulher, mãe, esposa, profissional, amiga, filha e neta. Para o autor, essa mudança de identidade de filha-de-sua-mãe para mãede-sua-filha pode estar relacionada a um sentimento de perda que explicaria, em parte, o surgimento dos sintomas de depressão.

Em relação aos casos estudados, pode-se afirmar que, além dos questionamentos sobre o relacionamento conjugal, o relacionamento das novas mães com as suas próprias mães esteve no centro desse realinhamento, corroborando a concepção de que a transformação na identidade de filha para mãe merece uma atenção especial (Stern, 1997). No caso de Paula, ela associou a sua história de vida à história de vida da própria mãe, demonstrando uma dupla identificação: ao mesmo que se identificava com sua mãe (que teve um aborto e a perda de uma filha com seis meses de vida - idade bastante semelhante à de sua filha no momento da entrevista), 
identificava-se também com o seu bebê (que, assim como ela, sofreria a "perda" da mãe que se afastaria para trabalhar). Pode-se pensar que, de alguma forma, ela associasse as perdas vividas pela própria mãe ao fato de ter se afastado de casa para trabalhar.

Já as falas de Andréa acerca do seu relacionamento com sua própria mãe também apontaram para a ocorrência de um realinhamento psíquico. Assim, o nascimento da filha teria desencadeado nela o desejo de realinhar a sua identidade como mulher, mãe e filha, embora houvesse muito tempo que os seus familiares chamavam a sua atenção para a necessidade de ser mais ativa frente à resolução de problemas. Mais do que isso, é possível pensar que a chegada da filha tenha possibilitado uma re-atualização de situações vividas entre Andréa e sua mãe, tamanha a mobilização de ambas naquele momento.

\section{Considerações Finais}

Como foi visto acima, a análise conjunta realizada permitiu a identificação de semelhanças e particularidades nas representações de cada uma das mães entrevistadas. Os resultados encontrados apoiaram a expectativa inicial de que a presença da depressão no período pós-parto estaria associada à ocorrência de algumas representações negativas acerca da maternidade, tais como: o sentimento de não ser capaz de cuidar do bebê, de não conseguir entender as suas necessidades, e de se sentir pouco apoiada pelo companheiro em relação aos cuidados com o bebê.

Além disso, a análise de seus relatos remete fundamentalmente à constatação de que os discursos de ambas as mães estiveram voltados para os mesmos temas: as suas preocupações com o bebê, com o apoio de seus familiares e com a necessidade de conciliar antigos e novos papéis. Assim, verificou-se nas falas das duas mães um importante movimento de reorganização mental, o qual corrobora a literatura a respeito da constelação da maternidade que envolve a mãe após o nascimento de um filho (Stern, 1997).

Nesse sentido, é plausível pensar que o modelo de entendimento das vicissitudes da maternidade proposto por Stern (1997) é de grande valia para a compreensão das interações iniciais entre mãe e bebê e das mudanças que se operam nas demais instâncias da vida da mulher nesse período. Porém, mais do que isso, os resultados do presente estudo sugerem que, para os casos estudados, a escolha de dois dos quatro temas da constelação da maternidade como eixos interpretativos para o exame das representações maternas em situação de depressão da mãe foi bastante útil como um modelo de compreensão da dinâmica familiar ao longo do primeiro ano de vida do bebê: o tema da matriz de apoio e o tema da reorganização da identidade.

Diante das evidências das repercussões da depressão pós-parto para a interação familiar e as delicadas trans- formações inerentes ao processo de construção da maternidade, é muito importante que os psicoterapeutas e os demais profissionais da área da saúde atentem cada vez mais para a necessidade de se intervir precocemente nessas situações. Nesse sentido, a escuta das representações maternas torna-se imprescindível para o planejamento de estratégias de prevenção e intervenções voltadas para a interação mãe-pai-criança.

\section{Referências}

Anderson, V., Fleming, A., \& Steiner, M. (1994). Mood and the transition to motherhood. Journal of Reproductive and Infant Psychology, 12(2), 69-77.

Beck, A. T., \& Steer, R. A. (1993). Beck Depression Inventory. Manual. San Antonio, TX: Psychological Corporation.

Brown, S., Lumley, J., Small, R., \& Astbury, J. (1994). Missing voices: The experience of motherhood. New York: Oxford University Press.

Cunha, J. A. (2001). Manual da versão em português das Escalas Beck. São Paulo, SP: Casa do Psicólogo.

Cutrona, C., \& Troutman, B. (1986). Social support, infant temperament, and parenting self-efficacy: A mediational model of postpartum depression. Child Development, 57(6), 1507-1518.

Feldman, R. (2000). Parents' convergence on sharing and marital satisfaction, father involvement, and parent-child relationship at the transition to parenthood. Infant Mental Health Journal, 21(3), 176-191.

Field, T., Morrow, C., \& Adlestein, D. (1993). Depressed mother's perceptions of infant behavior. Infant Behavior and Development, 16(1), 99-108.

Fowles, E. (1996). Relationships among prenatal attachment, presence of postnatal depressive symptoms and maternal role attainment. Journal of the Society of Pediatric Nurses, 1(2), 75-82.

Grupo de Interação Social, Desenvolvimento e Psicopatologia, \& Núcleo de Infância e Família (1998). Ficha de contato inicial. Manuscrito não-publicado, Instituto de Psicologia, Universidade Federal do Rio Grande do Sul, Porto Alegre, RS.

Grupo de Interação Social, Desenvolvimento e Psicopatologia, \& Núcleo de Infância e Família (2003a). Entrevista diagnóstica. Manuscrito não-publicado, Instituto de Psicologia, Universidade Federal do Rio Grande do Sul, Porto Alegre, RS.

Grupo de Interação Social, Desenvolvimento e Psicopatologia, \& Núcleo de Infância e Família (2003b). Consentimento livre e esclarecido. Manuscrito não-publicado, Instituto de Psicologia, Universidade Federal do Rio Grande do Sul, Porto Alegre, RS.

Grupo de Interação Social, Desenvolvimento e Psicopatologia, \& Núcleo de Infância e Família (2003c). Entrevista sobre a gestação e o parto. Manuscrito não-publicado, Instituto de Psicologia, Universidade Federal do Rio Grande do Sul, Porto Alegre, RS.

Grupo de Interação Social, Desenvolvimento e Psicopatologia, \& Núcleo de Infância e Família (2003d). Entrevista sobre a experiência da maternidade. Manuscrito não-publicado, Instituto de Psicologia, Universidade Federal do Rio Grande do Sul, Porto Alegre, RS. 
Hock, E., \& DeMeis, D. (1990). Depression in mothers of infants: The role of maternal employment. Developmental Psychology, 26(2), 285-291.

Hopkins, J., Campbell, S. B., \& Marcus, M. (1987). Role of infant-related stressors in postpartum depression. Journal of Abnormal Psychology, 96(3), 237-241.

Klaus, M. H., Kennel, J. H., \& Klaus, P. (2000). Vinculo: Construindo as bases para um apego seguro e para a independência. Porto Alegre, RS: Artes Médicas.

Langer, M. (1986). Maternidade e sexo: Estudo psicanalítico e psicossomático. Porto Alegre, RS: Artes Médicas.

Laville, C., \& Dione, J. (1999). A construção do saber: Manual de metodologia de pesquisa em Ciências Humanas. Porto Alegre, RS: Artes Médicas.

Lovejoy, M. C., Graczyk, P. A., O’Hare, E., \& Neuman, G. (2000). Maternal behavior and parenting behavior: A metaanalytic review. Clinical Psychology Review, 20(5), 561-592.

Mebert, C. J. (1991). Dimensions of subjectivity in parent's ratings of infant temperament. Child Development, 62(2), 352-361.

Milgron, J., \& McCloud, P. (1996). Parenting stress and postnatal depression. Stress Medicine, 12(3), 177-186.

Panzarine, S., Slater, E., \& Sharps, P. (1995). Coping, social support and depressive symptoms in adolescent mothers. Journal of Adolescent Health, 17(2), 113-119.

Piccinini, C. A., Lopes, R. S., Alfaya, C., Schwengber, D. S., Frizzo, G., Mayor, I., et al. (2003). O impacto da Psicoterapia para a depressão pós-parto e para a interação pais-bebê: Estudo longitudinal do sexto ao décimo segundo mês vida do bebê. Manuscrito não-publicado, Instituto de Psicologia, Universidade Federal do Rio Grande do Sul, Porto Alegre, RS.

Reading, R., \& Reynolds, S. (2001). Debt, social disadvantage and maternal depression. Social Science \& Medicine, 53(4), 441-453.

Romito, P., Saurel-Cubizolles, M. J., \& Lelong, N. (1999). What makes new mothers unhappy: Psychological distress one year after birth in Italy and France. Social Science \& Medicine, 49(12), 1651-1661

Schwengber, D. D. S., \& Piccinini, C. A. (2003). O impacto da depressão pós-parto para a interação mãe-bebê. Estudos de Psicologia (Natal), 8(3), 403-411.

Schwengber, D. D. S., \& Piccinini, C. A. (2005). A experiência da maternidade no contexto da depressão materna no final do primeiro ano de vida do bebê. Estudos de Psicologia (Natal), 22(2), 143-156.

Stake, R. E. (1994). Handbook of qualitative research. London: Sage.

Stern, D. N. (1992). O mundo interpessoal do bebê: Uma visão a partir da Psicanálise e da Psicologia do Desenvolvimento (M. A. V. Veronese \& R. E. Starosta, Trads.). Porto Alegre, RS: Artes Médicas.

Stern, D. N. (1997). A constelação da maternidade: O panorama da psicoterapia pais/bebê. Porto Alegre, RS: Artes Médicas.

Whiffen, V. (1990). Maternal depressed mood and perceptions of child temperament. The Journal of Genetic Psychology, 151(3), 329-339. 